\title{
Formulation Development of Celecoxib Loaded Microsponges using Eudragit and Ethyl Cellulose
}

\author{
Vishwajeet Swami ${ }^{1,2, *}$, Amir A Shaikh², Pooja N Jadhav ${ }^{3}$, Rahul S Buchade ${ }^{2}$ \\ 'Dr. D.Y. Patil Institute of Pharmaceutical sciences and Research, Pimpri, Pune, Maharashtra, INDIA. \\ ${ }^{2}$ SCES's Indira College of Phamacy, Tathwade, Pune, Maharashtra, INDIA. \\ ${ }^{3}$ CAYMET's Siddhant College of Pharmacy, Sudumbare, Pune, Maharashtra, INDIA.
}

\begin{abstract}
Background: Microsponge is a class of dosage form containing porous nature containing drug that is targeted to achieve sustained action for prolong period. Microsponge based delivery system results in drug localization on skin surface and in epidermis without moving in systemic circulation to higher extent. Methods: Present study aims to formulate the microsponge containing celecoxib by quasi emulsification solvent diffusion method. Prepared formulations were evaluated for particle size, \% entrapment efficiency, production yield, surface morphology, etc. Results: Formulation F1 and E2 were considered as optimized formulation having drug loading $91 \pm 4.2 \%$ and $91 \pm 3.1 \%$ respectively. FTIR spectroscopy analysis indicated the chemically stable, crystalline nature of the drug in these microsponges. Small change in crystallinity of pure drug was observed in XRD study. SEM study shows good microsponge surface appearance with pores on surfaces. Average particle size of optimized
\end{abstract}

microsponge formulation $\mathrm{F} 1$ is found to be $48 \mu \mathrm{m}$ while $\mathrm{E} 2$ formulation gave microsponges with particle size of $33.7 \mu \mathrm{m}$. As the RPM was increased the microsponge's size was also decreased and formed microsponges were spherical and is having uniform nature. Conclusion: Finally it can be concluded that chemically stable, uniform and porous microspheres were formed using Eudragit L-100 and Ethyl cellulose.

Key words: Celecoxib, Quasi emulsification, Eudragit, Ethyl cellulose.

Correspondence

Mr. Vishwajeet Swami

Dr. DY Patil Institute of Pharmaceutical sciences and research, Pune,

Maharashtra-411018, INDIA

Email: amirshaikhamu@gmail.com

DOI: 10.5530/ijpi.2021.2.40

\section{INTRODUCTION}

Topical drug delivery defined as application dosage form containing API effectively to skin for treatment of topical disorders. ${ }^{1}$ Microsponge is polymeric drug delivery system containing porous microspheres basically used for topical administration of large no of active pharmaceutical ingredients such as antifungal, anti-infective and inflammatory agents. ${ }^{2}$ Drugs administered through microsponge has significant advantages such as dose reduction, stability enhancement, lesser side effects, and most prominently modified drug release profile. $^{3}$

Loading of a drug into microsponge takes place by two processes. First is liquid-liquid suspension polymerization and the second one is quasi emulsion solvent diffusion method. In the second method, the microsponge was prepared by using different concentrations of polymers. $^{4}$

In allergic and inflammatory diseases mycology infections play an important role. There is some treatment is available for fungal infections. These infections prominently detected and spread in countries whose health system in poor and mainly in bellow poor countries having low income. ${ }^{5}$ Celecoxib is a class II drug produces irritation when taken internally so it is necessary to make formulation that gives sustained action when applied locally. Direct contact of celecoxib with the skin is avoided to reduced skin irritation, Current research work oriented towards design and characterization of celecoxib microsponge to improve release characteristics of celecoxib after entrapment into microsponges as well as to improve localized delivery of celecoxib to the skin which reduces systemic absorption.

\section{MATERIALS AND METHODS}

\section{Materials}

Celecoxib was provided by Lupin Research Park, Pune, India. Eudragit L-100, Ethyl cellulose, Ethyl cellulose and Carbapol 940 were obtained Analab Fine Chemicals, Mumbai, India. All other reagents and chemicals were of analytical grade.

\section{Methods}

Design Expert V10 software was used for formulation development. A CCD with $\alpha=1$ was employed as per standard protocol. ${ }^{6}$ The concentration of polymers and RPM were selected as experimental factors. All other ingredients and variables were kept constant for the study. Thirteen runs with various combinations of factors were obtained by design expert software as depicted in Table 1.

\section{Preparation of standard calibration curve of celecoxib in Phosphate buffer pH 6.8}

The UV spectrum of Celecoxib was obtained using UV spectrophotometer. Weighed $10 \mathrm{mg}$ of pure drug was dissolved in the $10 \mathrm{ml}$ Phosphate buffer to make a concentration of $1000 \mu \mathrm{g} / \mathrm{ml}$ (Stock-I). From the stock-I, $1 \mathrm{ml}$ of aliquot was withdrawn and transferred to a $100 \mathrm{ml}$ volumetric flask and made up the volume with Phosphate buffer to obtain a concentration of $10 \mu \mathrm{g} / \mathrm{ml}$ (Stock-II). From the stock solutionII aliquots of $0.2 \mathrm{ml}, 0.4 \mathrm{ml}, 0.6 \mathrm{ml}, 0.8 \mathrm{ml}, 0.10 \mathrm{ml}, 0.12 \mathrm{ml}$ were withdrawn and transferred into $10 \mathrm{ml}$ volumetric flask and made up the volume with buffer to obtain a concentration of $2 \mu \mathrm{g} / \mathrm{ml}, 4 \mu \mathrm{g} / \mathrm{ml}, 6 \mu \mathrm{g} / \mathrm{ml}, 8 \mu \mathrm{g} / \mathrm{ml}, 10$ $\mu \mathrm{g} / \mathrm{ml}, 12 \mu \mathrm{g} / \mathrm{ml}, 14 \mu \mathrm{g} / \mathrm{ml}$ respectively. The absorbance of solutions were 
measured using the Schimadzu1700 UV -Visible Spectrophotometer at the absorbance maximum $(\lambda \max )$ of $255 \mathrm{~nm}$.

\section{Method of Preparation of microsponges}

Microsponges were prepared by quasi emulsification approach. Inner phase comprise of eudragit L-100 disintegrated in $20 \mathrm{ml}$ of methanol. The blend was then filled the $0.75 \% \mathrm{w} / \mathrm{v}$ watery arrangement of poly vinyl alcohol which filled in as external phase. The blend was mixed at prescribed speed following $3 \mathrm{hr}$ of mixing. Microsponges were shaped due to removal of methanol from the framework by evaporation. The microsponge were washed with water, shifted and dried at $40^{\circ} \mathrm{C}$ for 12 hr. in hot air oven. ${ }^{7}$

\section{Evaluation of microsponges}

FTIR Study: The FTIR spectra of samples were recorded on shimadzu 640 IR instrument utilizing $\mathrm{KBr}$ plate method.10mg of dried example was blended with $40 \mathrm{mg}$ of $\mathrm{KBr}$ by utilizing a perfect glass pestle and mortar. The blended homogenized powder was packed in an IR pellet machine to get the pellets. ${ }^{8}$ The spectra was recorded at $400-4000 \mathrm{~cm}^{-1}$

XRD Study: X-ray beam powder diffraction were recorded utilizing a Philips X'pert master powder diffractometer with monochromatized CuK a Radiation $(\lambda=1.54056)$. The tests were checked at room temperature in the constant output mode over the 50 to $5002 \theta$ range with a $0.12 \theta$ step size and with an counting time of $0.6 \mathrm{sec}{ }^{9}$

Table 1: Design suggested by Central composite design for celecoxib microsponge preparation using a) Eudragit b) thylcellulose.

\begin{tabular}{|c|c|c|}
\hline Formulation & EUDRAGIT & RPM \\
\hline $\mathrm{F} 1$ & 562.5 & 600 \\
\hline $\mathrm{F} 2$ & 1000 & 800 \\
\hline F3 & 1000 & 400 \\
\hline $\mathrm{F} 4$ & 125 & 800 \\
\hline F5 & 562.5 & 600 \\
\hline F6 & 1181.22 & 600 \\
\hline F7 & 56.21 & 600 \\
\hline F8 & 562.5 & 882.84 \\
\hline F9 & 562.5 & 600 \\
\hline F10 & 125 & 400 \\
\hline F11 & 562.5 & 600 \\
\hline F12 & 562.5 & 317.15 \\
\hline F13 & 562.5 & 600 \\
\hline Formulation & ETHYL CELLULOSE & RPM \\
\hline E1 & 86.39 & 600 \\
\hline E2 & 550 & 600 \\
\hline E3 & 100 & 400 \\
\hline $\mathrm{E} 4$ & 550 & 317.15 \\
\hline E5 & 550 & 600 \\
\hline E6 & 1000 & 800 \\
\hline E7 & 1000 & 400 \\
\hline E8 & 550 & 600 \\
\hline E9 & 550 & 882.84 \\
\hline E10 & 500 & 600 \\
\hline E11 & 1180.4 & 600 \\
\hline E12 & 100 & 800 \\
\hline E13 & 550 & 600 \\
\hline
\end{tabular}

Surface morphology of microsponges: Surface morphology and topography was studied by scanning electron microscopy (SEM). Gold palladium was used to coat the developed sample of microsponge at room temperature under an argon atmosphere and surface morphology was studied with SEM. ${ }^{10}$

Particle size determination: Optical microscopy is used for the particle size determination of microsponges. Ocular micrometer and a stage micrometer was fitted with an optical microscope. Calibration of eyepiece micrometer was done. 50 particles were measured randomly by optical microscope for diameter. ${ }^{11}$

Percentage production yield: Percent production yield was calculated by weighing of microsponge recovered from each batch in comparison with the sum of initial weights of starting materials. ${ }^{12}$

$\%$ yield $\frac{\text { Practical Mass (Microsponge) }}{\text { Theoretical Mass (Polymer + Drug) }}$

Determination of drug loading Efficiency: Drug-loaded Microsponge $(100 \mathrm{mg})$ were digested with acetonitrile $10 \mathrm{ml}$ at room temperature for $12 \mathrm{~h}$. Suitable dilutions and filtration was done and amount of Celecoxib in the solution was obtained using a UV visible spectrophotometer. ${ }^{13}$ Following formula used for determination of loading of drug in microparticles:

$\mathrm{L} \frac{\mathrm{Qm}}{\mathrm{Wm}} \times 100$

Where, L: Percentage loading of microsponge, Qm: Quantity of the drug, Wm: Weight of microparticles.

\section{RESULTS}

\section{Calibration curve of celecoxib in $\mathrm{pH} 6.8$ Phosphate buffer}

Calibration curve of Celecoxib in Phosphate Buffer Solution pH 6.8 showed the straight line which passes from origin. Line showed the equation $\mathrm{Y}=0.0898 \mathrm{X}+0.0107\left(R^{2}=0.9995\right)$. The obtained curve showed linearity in the concentration range of $2-20 \mu \mathrm{g} / \mathrm{ml}$ at $255 \mathrm{~nm}$. Regression coefficient was found to be 0.998 , which indicates linearity of absorbance in the range $2-20 \mu \mathrm{g} / \mathrm{ml}$.

\section{Evaluation of prepared Microsponges}

FTIR study of prepared microsponges: The compatibility between drug and polymer were detected by FTIR studies. The FTIR spectra of drug and microsponge formulations were obtained using Jasco FT-IR(4200). The spectra were recorded over the wave number range of 400 to $4000 \mathrm{~cm}-1$. The celecoxib FTIR spectra (Figure 1) showed a characteristic $\mathrm{S}=\mathrm{O}$ asymmetric and symmetric stretching at 1347 and $1164 \mathrm{~cm}^{-1}$, respectively. Medium intensity bands at 3338 and $3232 \mathrm{~cm}^{-1}$ were seen as a doublet, which are attributed to the $\mathrm{N}-\mathrm{H}$ stretching vibration of $\mathrm{SO}_{2} \mathrm{NH}_{2}$ group. a)

X-Ray Diffraction study: X-ray diffractometry of celecoxib exhibited sharp intense diffraction peaks indicating a crystalline nature. The diffraction peaks were reduced in the case of the binary celecoxib to smaller extent. X-ray diffraction pattern of selected formulation is shown in Figure 2.

Scanning Electron Microscopy study: Morphology of EudragitCelecoxib microsponge was investigated by scanning electron microscopy. Microsponge were found to be rough surface with pores on surface with devoid of cracks giving them good appearance. The SEM data obtained on drug loaded microsponges were shown in Figure 3.

Determination of Percentage Yield: From the result it was noted that as drug polymer ratio increases there is increases in the percentage 
yield. The percentage yield of prepared 13 formulations of Eudragit microsponges were in the range of $74.13 \pm 2.7$ to $91.14 \pm 1.6$. For Ethyl cellulose microsponge the percentage yield of prepared 13 formulations were in the range of $72.15 \pm 2.4$ to $91.19 \pm 2.2$.

Particle size determination: The microsponges average particle size should be between 5-300 $\mu \mathrm{m}$. Optical microscopy used in all batches for particle size analysis showed that as drug: Polymer ratio increases there is increase in particle size. As shown in Table 2 Final batch (F1) contain more percent of uniform and spherical particles during study. The results revealed average particle size of $48 \mu \mathrm{m}$. E2 formulation by using ethyl cellulose gave average particle size of $33.7 \mu \mathrm{m}$.

Determination of percent drug loading: From the result it can be noted that as the polymer concentration increases Percent drug loading also increases. Percent drug loading of prepared 13 formulations of Eudragit microsponges were in the range of $89 \pm 2.4$ to $92 \pm 2.6$, while formulations containing ethyl cellulose showed range of $88 \pm 2.4$ to $92 \pm 1.6$ of percent drug loading.

\section{DISCUSSION}

Microsponges of celecoxib were prepared by quassi emulsification solvent diffusion technique. Eudragit and ethyl cellulose were used for development of microsponges. The IR spectrum obtained of celecoxib


Figure 1: FTIR spectra of a) Pure Celecoxib b) Eudragit and celecoxib Microsponge c) Ethyl Cellulose and celecoxib Microsponge. with polymers shows characteristic absorption peaks of drug at proper position indication no interaction between drug and polymer.

$\mathrm{X}$-ray powder diffraction was used for checking the presence of polymorphs or modifications in drug crystals. All the samples showed similar positions of peak ( $2 \theta$ values) in spectra. Hence, chances related to presence of various polymorphs of celecoxib in these formulations was ruled out. The data obtained indicate that the initial crystalline nature of celecoxib has been altered slightly in the formulation this might be because of the effect of amorphous nature of polymer.

SEM analysis revealed that there is formation of pores in microsponges. This may be due to solvent diffusion from microsponges surface. Moreover, it was noted that the internal structure made of spherical cavity enclosing drug and polymer. In quasi emulsion technique there is good affinity between drug and good solvent as compared to the affinity between poor solvent and good solvent. Solution of drug in the good solvent makes emulsion droplets (quasi) upon addition into the poor solvent, in to the external phase the organic phase then diffused which results in pores formation of very small size particles, known as microsponges which takes spherical shape because of constant agitation. ${ }^{14}$ Another parameter which is influenced from drug: polymer ratio change is particle size. It has been observed that as the drug ratio is increased, particle size of microsponge is additionally expanded. It may be because at a higher drug: Polymer ratio polymer available was more hence greater
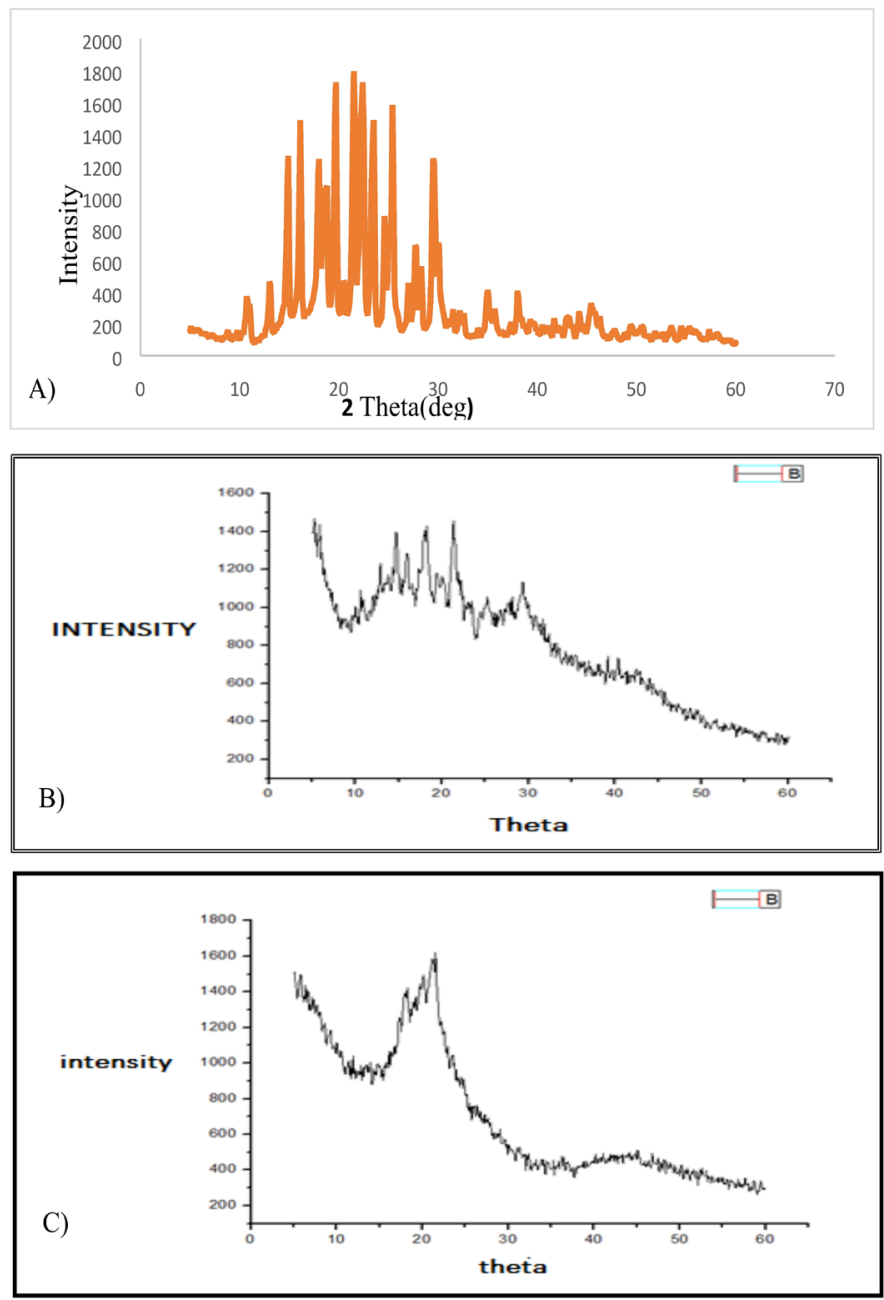

Figure 2: a) XRD of Pure Celecoxib b) XRD of Eudragit microsponges c) XRD of Ethyl cellulose microsponges. 


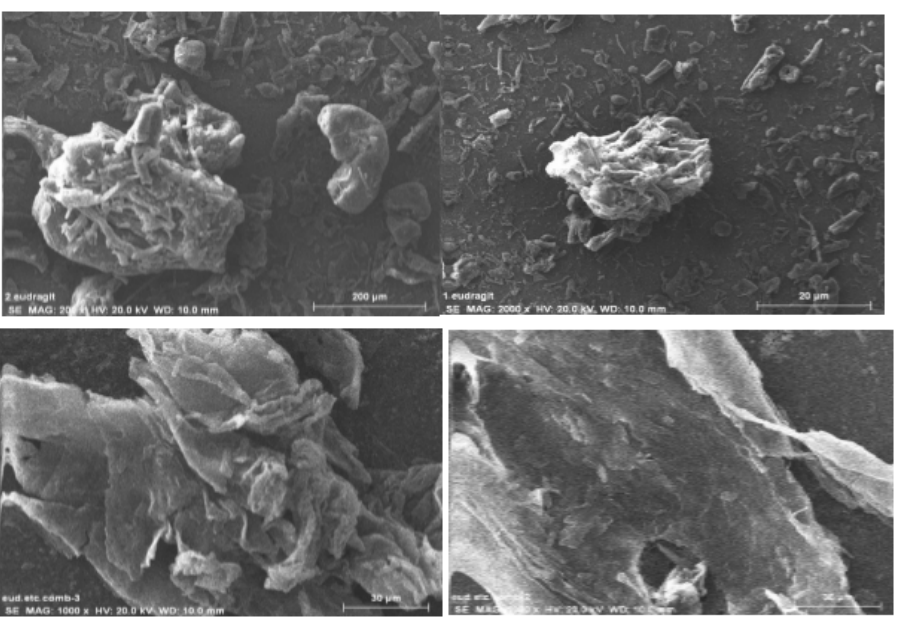

Figure 3: SEM for microsponges of drug and a) Eudragit b) Ethyl cellulose.

\section{Table 2: Particle size determination of Eudragit and Ethyl cellulose microsponges.}

\begin{tabular}{|c|c|c|c|c|}
\hline $\begin{array}{l}\text { Sr. } \\
\text { No. }\end{array}$ & $\begin{array}{l}\text { Number of Lines } \\
\text { On Oculometer } \\
\text { for Eudragit } \\
\text { microsponges }\end{array}$ & $\begin{array}{l}\text { (Average) } \\
\text { Actual } \\
\text { Length In } \\
\mu \mathrm{M}\end{array}$ & $\begin{array}{l}\text { Number of } \\
\text { Lines On } \\
\text { Oculometer for } \\
\text { Ethyl cellulose } \\
\text { microsponges }\end{array}$ & $\begin{array}{c}\text { (Average) } \\
\text { Actual } \\
\text { Length In } \\
\mu \mathrm{M}\end{array}$ \\
\hline 1 & $\begin{array}{l}\text { 10x7.5correction } \\
\text { factor }\end{array}$ & 75 & $\begin{array}{l}7 \times 7.5 \text { correction } \\
\text { factor }\end{array}$ & 52.5 \\
\hline 2 & $\begin{array}{l}5 \times 7.5 \text { correction } \\
\text { factor }\end{array}$ & 37.5 & $\begin{array}{l}2 \times 7.5 \text { correction } \\
\text { factor }\end{array}$ & 15 \\
\hline 3 & $\begin{array}{l}6 \times 7.5 \text { correction } \\
\text { factor }\end{array}$ & 45 & $\begin{array}{l}6 \times 7.5 \text { correction } \\
\text { factor }\end{array}$ & 45 \\
\hline 4 & $\begin{array}{l}7 \times 7.5 \text { correction } \\
\text { factor }\end{array}$ & 52.5 & $\begin{array}{l}2 \times 7.5 \text { correction } \\
\text { factor }\end{array}$ & 15 \\
\hline 5 & $\begin{array}{l}2 \times 7.5 \text { correction } \\
\text { factor }\end{array}$ & 15 & $\begin{array}{l}4 \times 7.5 \text { correction } \\
\text { factor }\end{array}$ & 30 \\
\hline 6 & $\begin{array}{l}4 \times 7.5 \text { correction } \\
\text { factor }\end{array}$ & 30 & $\begin{array}{l}9 \times 7.5 \text { correction } \\
\text { factor }\end{array}$ & 67.5 \\
\hline 7 & $\begin{array}{l}6 \times 7.5 \text { correction } \\
\text { factor }\end{array}$ & 45 & $\begin{array}{l}5 \times 7.5 \text { correction } \\
\text { factor }\end{array}$ & 37 \\
\hline 8 & $\begin{array}{l}8 \times 7.5 \text { correction } \\
\text { factor }\end{array}$ & 60 & $\begin{array}{l}3 \times 7.5 \text { correction } \\
\text { factor }\end{array}$ & 22.5 \\
\hline 9 & $\begin{array}{l}7 \times 7.5 \text { correction } \\
\text { factor }\end{array}$ & 52.5 & $\begin{array}{l}4 \times 7.5 \text { correction } \\
\text { factor }\end{array}$ & 30 \\
\hline \multirow[t]{2}{*}{10} & $\begin{array}{l}9 \times 7.5 \text { correction } \\
\text { factor }\end{array}$ & 67.5 & $\begin{array}{l}3 \times 7.5 \text { correction } \\
\text { factor }\end{array}$ & 22.5 \\
\hline & AVERAGE & 48 & AVERAGE & 33.7 \\
\hline
\end{tabular}

size of microsponges were obtained because of increasing polymer wall thickness. Also increase in polymer concentration has direct correlation on viscosity of the internal phase; hence larger size globules are formed which results in greater mean particle sizes.

Stirring rate also plays an important role in deciding the particle size of microsponges. Agitation speed plays an important role on addition of the drug and polymer into the aqueous phase. As the RPM was increased there is decrease in the size of microsponges and formed microsponges were spherical and uniform in nature. It is general observation that increase in the polymer ratio increases the drug loading. It may be because grater the polymer ratio results in reduction in diffusion rate of drug solution from concentrated polymeric solutions into external phase. This results in higher time for the droplet formation and may increases the microsponge yield and drug loading. Moreover the polymer-drug association also retards evaporation of the solvent at molecular level which results in an improved drug precipitation in the microsponges.

\section{CONCLUSION}

Celecoxib microsponges were prepared by quasi emulsion solvent diffusion method. Eudragit L-100, ethyl cellulose polymer were used for preparation of microsponges. Formulation F1 and E2 were considered as optimized formulation having drug loading $91 \pm 4.2 \%$ and $91 \pm 3.1 \%$ respectively. FTIR spectroscopy analysis indicated the chemically stable, crystalline nature of the drug in these microsponges. Small change in crystallinity of pure drug was observed in XRD study. SEM study shows good microsponge surface appearance with pores on surfaces. Average particle size of optimized microsponge formulation F1 is found to be $48 \mu \mathrm{m}$ while E2 formulation gave microsponges with average particle size of $33.7 \mu \mathrm{m}$. Stirring rate also plays an important role in deciding the particle size of microsponges. Increased RPM results in reduction in size of microsponges and formed microsponges were of uniform and spherical in nature. After comparing all the results obtained it can be concluded that both polymers (Eudragit L-100 and Ethyl cellulose) can be successfully utilize for formulation of celecoxib microsponges using quasi emulsification solvent diffusion method.

\section{ACKNOWLEDGEMENT}

The authors are thankful to SCES's Indira College of Pharmacy, Pune, and Dr. D.Y. Patil Institute of Pharmaceutical sciences and Research, Pune, for providing necessary facility and infrastructure to conduct this research work. The authors are grateful to Lupin Research Park, Pune and Analab Fine Chemicals, Mumbai, for providing the gift samples.

\section{CONFLICT OF INTEREST}

The authors declare that there is no conflict of interest.

\section{ABBREVIATIONS}

API: Active pharmaceutical Ingredient; CCD: Central composit design; RPM: Revolution per minute; FTIR: Fourier-transform infrared spectroscopy; XRD: X-ray powder diffraction; SEM: Scanning electron microscopy.

\section{REFERENCES}

1. Krantikumar K, Sasikanth K, Sabareesh M, Dorabaru N. Formulation and evaluation of diacerein cream. Asian J Pharm Clin Res. 2011;4(2):93-8.

2. Meenakshi D. Emulgel: A novel approach to topical delivery. Int J Pharma and Bio Sci. 2013;4:847-56.

3. Shaha $V$, Jain $H$, Krishna J, Patel P. Microsponge drug delivery: A review. Int J Res Pharm Sci. 2010;1:212-8.

4. Aldawsari $H$, Shalmaa M, Eldin B. Microsponge as a promising vehicle for drug delivery and targeting: Preparation, characterization and applications. Asian J Pharm and Pharmaco. 2013;7(17):873-81.

5. Badiee P, Hashemizadeh Z. Opportunistic invasive fungal infections: Diagnosis and clinical management. Indian J Med Res. 2014;139(2):195-204.

6. Shaikh AA, Chaudhari PD, Holkar SS. A design of experiment approach for optimisation and characterization of etodolac ternary system using spray drying. Int J Pharm Pharm Sci. 2017;9(2):233-40.

7. Jain V, Singh R. Development and characterization of eudragit RS 100 loaded microsponges and its colonic delivery using natural polysaccharides. Acta Po- 
Ioniae Pharm Drug Res. 2010;67(4):407-15.

8. Galatage ST. Development and characterization of microsponge of amphotericin B for topical drug delivery. Res J Pharm Biol Chem Sci. 2019;10(1):1288-300

9. Shaikh AA, Chaudhari PD, Lavate PK. Central composite design for enhancement of etodolac solubility via inclusion complexation with PVP k-30 and $\mathrm{Hy}$ droxypropyl $\beta-C y c l o d e x t r i n$. European Journal of Pharmaceutical and Medical Research. 2017;4(2):657-63.

10. Lachman L, Liebermann HA, Kanig JL. The Theory and Practice of Industrial Pharmacy, $3^{\text {rd }}$ Edition, Varghese Publishing House, New Delhi;1987;180.

11. Srinivas S, Kumar AY, Hemanth A, Anitha M. Preparation and evaluation of nio- somes containing aceclofenac digest. Journal of Nanomaterials and Biostructures; 2010;5(1):249-54.

12. Vesselin NP. Fabrication of Novel Types of Colloidosome Microcapsules for Drug Delivery Applications. Materials Research Society Symposium Proceedings. 2004;845(1):140-4.

13. Singh C, Jain CP, Narendrakumar B. Formulation and characterization of stability and in vitro evaluation of nimusulide niosomes. Pharmaco and Int Res J. 2011;3(3):168-85

14. Pande VV, Kadnor NA, Kadam RN, Upadhye SA. Fabrication and Characterization of Sertaconazole Nitrate Microsponge as a Topical Drug Delivery System. Indian J Pharm Sci. 2015;77(6):675-80.

Article History: Submission Date : 16-03-2021; Revised Date : 11-04-2021; Acceptance Date : 17-06-2021.

Cite this article: Swami V, Shaikh AA, Jadhav PN, Buchade RS. Formulation Development of Celecoxib Loaded Microsponges using Eudragit and Ethyl Cellulose. Int. J. Pharm. Investigation, 2021;11(2):225-9. 